\title{
Mechanism of Perfluoropolyether Chains Bonding on Carbon Overcoat Surface by Ultraviolet Irradiation
}

\author{
Takayuki Nakakawaji $1^{1)^{*}}$, Mina Amo ${ }^{1)}$, Hiroyuki Matsumoto ${ }^{2)}$, \\ Teiji Kato ${ }^{3)}$ and Ken-ichi Iimura ${ }^{3)}$ \\ ${ }^{1)}$ Materials Research Laboratory, Hitachi, Ltd. \\ 7-1-1 Omika-cho, Hitachi-shi, Ibaraki 319-1292, Japan \\ ${ }^{2)}$ Central Research Laboratory, Hitachi, Ltd. \\ 2880 Kozu, Odawara-shi, Kanagawa 256-8510, Japan \\ ${ }^{3)}$ Graduate School of Engineering, Utsunomiya University \\ 7-1-2 Yoto, Utsunomiya-shi, Tochigi 321-8585, Japan \\ *Corresponding author: takayuki.nakakawaji.js@hitachi.com
}

( Manuscript received 13 April 2009; accepted 13 July 2009; published 31 July 2009 )

To elucidate the bonding mechanism of a non-polar perfluoropolyether lubricant (PFPE lube) under ultraviolet (UV) irradiation, the UV wavelength ranges in which photoelectrons emanate were identified using photoelectron spectroscopy in air (PESA), and the bonding behavior of the lube at various UV wavelengths was studied. The results showed that photoelectrons emanated from magnetic disk substrates at wavelengths of $240 \mathrm{~nm}$ or less and the lube was bonded to the substrate in the wavelength range where photoelectrons were emanated. For comparison, $\mathrm{Si}, \mathrm{SiO}_{2} / \mathrm{Si}$, and $\mathrm{Si}_{3} \mathrm{~N}_{4} / \mathrm{Si}$ were also used as substrate; the $\mathrm{Si}$ substrate which emanated the highest photoelectron intensity showed the highest bonded ratio of the lube. The lube, however, also bonded to the $\mathrm{SiO}_{2} / \mathrm{Si}$ and $\mathrm{Si}_{3} \mathrm{~N}_{4} / \mathrm{Si}$ substrates under UV irradiation at $222 \mathrm{~nm}$, where photoelectrons do not emanate from the substrates. These observations suggest that the bonding mechanism between the PFPE chains and the carbon overcoat (COC) surfaces under UV irradiation was affected by factors other than photoelectrons.

Keywords: hard disk, perfluoropolyether, UV irradiation, photoelectron, photo-dissociation

\section{Introduction}

The recent trend toward increased magnetic recording density has led to lower flying height, which is now less than $5 \mathrm{~nm}$. It is important to ensure reliability against head-disk contact sliding that inevitably occurs during hard disk drive operation. Perfluoropolyether (PFPE) lubricants are employed in the magnetic recording industry as surface lubricants for the magnetic recording disks. In order to secure the tribological reliability between the head and disk, strong bonding of PFPE lubricant layer on the carbon overcoat (COC) surface is needed. UV irradiation treatment is one of possible approaches to increase the bonding strength of the lubricant film to the substrate surface. However, there is considerable uncertainty about the mechanism of UV bonding of lubricants. Therefore, it is important to elucidate this bonding mechanism in order to improve the processes of forming lubricant films and to develop the new lubricants.
There have been several reports on the bonding of PFPE lubricants to the carbon overcoat surface under UV irradiation $^{1-13)}$. Vurens et al. supposed that the bonding is caused by photoelectrons generated from the COC surface $^{2,3)}$. On the contrary, Guo and Waltman et al. concluded that partial photo-dissociation of the PFPE chains due to UV irradiation was the main factor behind the bonding ${ }^{12,13)}$. In this study, to elucidate the UV-induced PFPE chains bonding mechanism, dependency of photoelectron generation from solid substrates on UV wavelength was examined by photoelectron spectroscopy in air (PESA). The lube bonding behavior at different UV wavelength was also studied by comparison of lube bonded ratio, defined as the ratio of film thickness retained by the solid surfaces after being rinsed in solvent to that just after UV irradiation. If a PFPE lubricant has polar groups, photochemical reactions will occur at the PFPE chains and the polar groups together with bonding under UV irradiation, which makes the mechanism quite 
complicated. Therefore, we used non-polar PFPE lubricants to focus on a bonding mechanism ascribable to the PFPE chains.

\section{Experimental}

The lubricant used in this study was a non-polar PFPE lubricant (Z25; manufactured by Solvay Solexis; hereafter referred to as the lubricant). The molecular structure and number-average molecular weight $(\mathrm{Mn})$ of Z25 are shown below.

$$
\left.\mathrm{CF}_{3}-\mathrm{CF}_{2} \mathrm{O} \text { f } \mathrm{CF}_{2} \mathrm{CF}_{2} \mathrm{O}\right\}_{\mathrm{m}}\left(\mathrm{CF}_{2} \mathrm{O}_{\mathrm{n}} \mathrm{CF}_{2}-\mathrm{CF}_{3}\right.
$$

(Mn 9500)

The substrates used in this study are a magnetic disk on which diamond-like carbon (DLC) had been deposited, Si substrate, Si substrate with $1000 \mathrm{~nm}$ of $\mathrm{SiO}_{2}$ film $\left(\mathrm{SiO}_{2} / \mathrm{Si}\right.$ substrate), and $\mathrm{Si}$ substrate with 200 $\mathrm{nm}$ of $\mathrm{Si}_{3} \mathrm{~N}_{4}$ film $\left(\mathrm{Si}_{3} \mathrm{~N}_{4} / \mathrm{Si}\right.$ substrate). The lubricant was dissolved in a fluorine solvent (HFE7100; manufactured by Sumitomo 3M Ltd.) to give a desired concentration and deposited onto substrates by dip coating. The film thicknesses, measured by a Fourier Transform Infrared Spectrophotometer (FT-IR) and X-ray Photoelectron Spectroscopy (XPS), were approximately $1.0 \mathrm{~nm}$. In the FT-IR measurement, the film thickness was obtained by converting the peak intensities of the CF stretching bands of a sample into the film thickness by comparing the peak intensities with those of reference samples with known film thickness (determined by an ellipsometer or by X-ray reflectivity). The bonding of the lubricant under UV irradiation was estimated by the ratio of film thickness retained by the solid surfaces after being rinsed in solvent to that just after UV irradiation (lube bonded ratio, hereafter referred to as the LBR). A UV lamp that could produce four different wavelengths was used for irradiation. The UV lamp and irradiation conditions used in this study are as follows.

UV lamp:

$254 \mathrm{~nm}$ (Low pressure mercury lamp)

$222 \mathrm{~nm}$ ( $\mathrm{KrCl}$ Excimer lamp)

$185 \mathrm{~nm}$ (Low pressure mercury lamp)

$172 \mathrm{~nm}$ (Xe Excimer lamp)

Integrated luminous energy and irradiation time:

$480 \mathrm{~mJ} / \mathrm{cm}^{2}$

$254 \mathrm{~nm}: 37 \mathrm{sec}, 222 \mathrm{~nm}: 60 \mathrm{sec}, 185 \mathrm{~nm}: 216 \mathrm{sec}$, $172 \mathrm{~nm}: 61 \mathrm{sec}$

$320 \mathrm{~mJ} / \mathrm{cm}^{2}$

$254 \mathrm{~nm}: 25 \mathrm{sec}, 222 \mathrm{~nm}: 40 \mathrm{sec}, 185 \mathrm{~nm}: 144 \mathrm{sec}$, $172 \mathrm{~nm}: 40 \mathrm{sec}$

$160 \mathrm{~mJ} / \mathrm{cm}^{2}$

$254 \mathrm{~nm}: 13 \mathrm{sec}, 222 \mathrm{~nm}: 20 \mathrm{sec}, 185 \mathrm{~nm}: 72 \mathrm{sec}$, $172 \mathrm{~nm}: 20 \mathrm{sec}$
UV irradiation treatment was performed under $\mathrm{N}_{2}$ atmosphere (ozone concentration : $<0.05 \mathrm{ppm}$ ).

Photoelectrons emanated from the substrate surfaces were measured using PESA (AC-3; manufactured by Riken Keiki Co., Ltd.). PESA irradiates samples with UV light from a deuterium lamp (anode voltage $2.99 \mathrm{~V}$ ) with an energy scan range of 4.0-7.0 eV (310-177.1 nm) and then measures the photoelectrons with a $\mathrm{N}_{2}$-purged grating monochromator. The measurement luminous energy is $9.8 \mathrm{nW}$. The intensities of the photoelectrons emanating from the surfaces of four types of substrates and their threshold energies (UV wavelengths) were measured in this study.

\section{Results and discussion}

Figure 1 shows the change of photoelectron intensities as a function of UV wavelength measured by PESA for magnetic disks with or without the lubricant layer. For the disk without the lubricant, the photoelectrons started to be emanated at wavelengths of $240 \mathrm{~nm}$ or less and their intensity increased as the wavelength reduced, that is, as the photon energy increased. With the lubricant, the photoelectrons still emanated at wavelengths of $240 \mathrm{~nm}$ or less and the threshold energy was almost the same, but the intensity was lower.



Fig. 1 The relationship between the intensities of the photoelectrons emanating from disks and the UV wavelength

Figure 2 shows the LBR of the lubricant-coated disks irradiated with UV at four different wavelengths. The LBR of disks without UV irradiation as well as with UV irradiation at $254 \mathrm{~nm}$ (with $160 \mathrm{~mJ} / \mathrm{cm}^{2}$ and $320 \mathrm{~mJ} / \mathrm{cm}^{2}$ ) was $0 \%$.

However, at 222, 185, and $172 \mathrm{~nm}$, the lubricant was bonded and the LBR increased as the wavelengths reduced, that is, as the photon energies increased. In addition, the LBRs tended to be higher with the increase of integrated luminous energies. The UV wavelengths at which the bonding between the lub and the substrate was observed $(222,185$, and $172 \mathrm{~nm})$ were those at which photoelectrons emanated, $240 \mathrm{~nm}$ or less. Thus, the 
wavelength range where the bonding of the lubricant occurred corresponded with the wavelength range where photoelectrons emanated. In other words, it is supposed that the bonding of the lubricant is caused by photoelectrons.

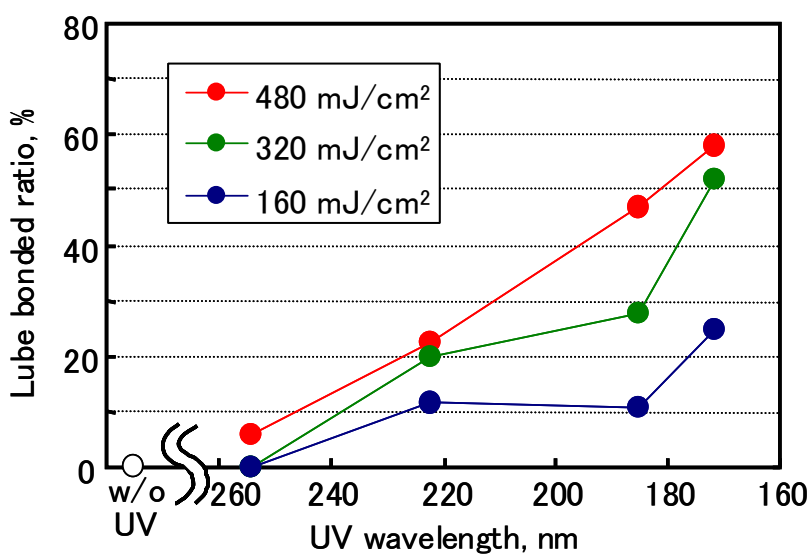

Fig. 2 Lube bonded ratio of the disks coated with the lubricant and then irradiated with UV at four different wavelengths

Figure 3 shows the photoelectron intensities measured using PESA when using a $\mathrm{Si}$ substrate, $\mathrm{SiO}_{2} / \mathrm{Si}$ substrate, and $\mathrm{Si}_{3} \mathrm{~N}_{4} / \mathrm{Si}$ substrate. In the case of the $\mathrm{Si}$ substrate, the photoelectrons emanated by irradiation of UV light of $250 \mathrm{~nm}$ or less. In the case of the $\mathrm{SiO}_{2} / \mathrm{Si}$ and $\mathrm{Si}_{3} \mathrm{~N}_{4} / \mathrm{Si}$ substrates, however, the photoelectrons emanated at $200 \mathrm{~nm}$ or less; that is, the threshold energy for photoelectron emission was high. Therefore, photoelectrons scarcely emanated from the $\mathrm{SiO}_{2} / \mathrm{Si}$ and $\mathrm{Si}_{3} \mathrm{~N}_{4} / \mathrm{Si}$ substrates under the $222 \mathrm{~nm}$ UV lamp used in this study.

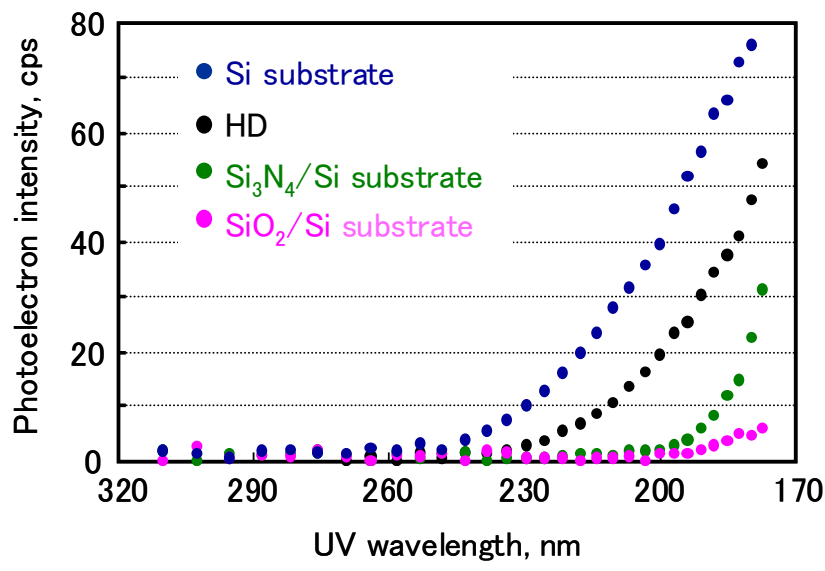

Fig. 3 The photoelectron intensities measured by PESA when using a $\mathrm{Si}$ substrate, $\mathrm{SiO}_{2} / \mathrm{Si}$ substrate, and $\mathrm{Si}_{3} \mathrm{~N}_{4} / \mathrm{Si}$ substrate as a function of $\mathrm{UV}$ wavelength
Figure 4 compares the LBRs for lubricant-coated $\mathrm{Si}$, $\mathrm{SiO}_{2} / \mathrm{Si}$, and $\mathrm{Si}_{3} \mathrm{~N}_{4} / \mathrm{Si}$, samples irradiated with UV light of 222,185 , and $172 \mathrm{~nm}$ wavelength respectively.

The integrated luminous energy at each UV wavelength was $480 \mathrm{~mJ} / \mathrm{cm}^{2}$. The Si substrate, emanated the largest number of from which photoelectrons in the three and its $\mathrm{LBR}$ was higher than that of the $\mathrm{SiO}_{2} / \mathrm{Si}$ and $\mathrm{Si}_{3} \mathrm{~N}_{4} / \mathrm{Si}$ substrates.

However, in the case of the $\mathrm{SiO}_{2} / \mathrm{Si}$ and $\mathrm{Si}_{3} \mathrm{~N}_{4} / \mathrm{Si}$ substrates, the lubricant was bonded at $222 \mathrm{~nm}$, where photoelectrons are barely emanated. This means that the bonding of the lubricant to the surfaces of $\mathrm{SiO}_{2} / \mathrm{Si}$ and $\mathrm{Si}_{3} \mathrm{~N}_{4} / \mathrm{Si}$ substrates under UV irradiation at $222 \mathrm{~nm}$ resulted from a factor other than photoelectrons.

The photon energies, $E$, at UV wavelength (of 254, 222,185 , and $172 \mathrm{~nm}$ ) were calculated from equation (1) to be $471,539,647$, and $696 \mathrm{~kJ} / \mathrm{mol}$, respectively.

$$
E=h c / \lambda
$$

where $h$ is Planck's constant $\left(6.626 \times 10^{-34} \mathrm{~J} \cdot \mathrm{s}\right), c$ is the velocity of light $\left(2.998 \times 10^{8} \mathrm{~m} / \mathrm{s}\right)$, and $\lambda$ is the wavelength of the electromagnetic wave $\left(10^{-9} \mathrm{~m}\right)$.

Table 1 lists the bonding energies of the chemical bonds in the lubricant. The photon energies are higher than the bonding energies, and therefore, UV irradiation of wavelengths of $222 \mathrm{~nm}$ or less can cause the dissociation of the chemical bonds listed in Table 1 .

In the case of the $\mathrm{SiO}_{2} / \mathrm{Si}$ and $\mathrm{Si}_{3} \mathrm{~N}_{4} / \mathrm{Si}$ substrates, it is supposed that partial photo-dissociation of the PFPE chains and subsequent generation of radicals on the PFPE chains at $222 \mathrm{~nm}$ caused bonding to the surface of the COC. So the partial photo-dissociation of PFPE film under UV irradiation is more likely dominant role in UV bonding of PFPE film. However lube bonding ratio depend on the intensity of photoelectrons emitted from substrate, and it cannot be denied that photoelectrons is not dominant role of UV bonding mechanisms.



Fig. 4 The lube bonded ratio of the $\mathrm{Si}, \mathrm{SiO}_{2} / \mathrm{Si}$, and $\mathrm{Si}_{3} \mathrm{~N}_{4} / \mathrm{Si}$ which were coated with the lubricant and irradiated at 222, 185 and 172 $\mathrm{nm}$ 
It is considered that bonding of the lubricant layer to the substrate surfaces was caused not only by photoelectrons emitted from the substrates but also by other factors such as the direct photo-dissociation of the PFPE chains by the high energy UV light.

Table 1 the bonding energies of the chemical bonds in the lubricant

\begin{tabular}{|c|c|c|}
\hline Chemical Bond & $\begin{array}{c}\text { Bonding Energy } \\
(\mathrm{kJ} / \mathrm{mol})\end{array}$ & $\begin{array}{c}\text { Light wave } \\
\text { length (nm) }\end{array}$ \\
\hline C-C & 348.2 & 344.7 \\
\hline C-O & 351.96 & 341 \\
\hline C-H & 413.97 & 289.9 \\
\hline C-F & 441.63 & 271.8 \\
\hline
\end{tabular}
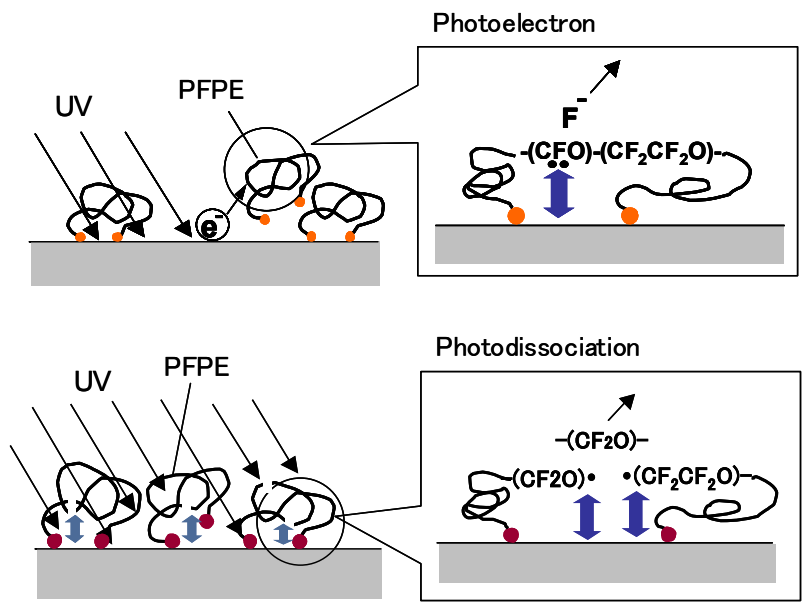

Fig. 5 The schematic diagrams of the presumed bonding mechanisms

\section{Conclusions}

The UV wavelength ranges in which photoelectrons emanate were identified using PESA, and the relationship between the photoelectron emission from UV irradiation and the bonding of the lubricant was studied. From this, it was found that the bonding of the lubricant under UV irradiation was caused not only by photoelectrons but also by other factors, as for example, the partial photo-dissociation of the PFPE chains.

\section{Acknowledgement}

The authors wish to express their sincere thanks to Dr. Nakajima for his help on the PESA analysis.

\section{References}

[1] Saperstein, D. D. and Lin, L. J., "Improved Surface Adhesion and Coverage of Perfluoropolyether Lubricants Following Far-UV Irradiation," Langmuir, 6, 1990, 1522-1524.

[2] Vurens, G. H., Gudeman, C. S., Lin, L. J. and Foster, J. S., "Mechanism of Ultraviolet and Electron Bonding of Perfluoropolyethers," Langmuir, 8, 1992, 1165-1169.

[3] Vurens, G. H., Gudeman, C. S., Lin, L. J. and Foster, J. S., "The Mechanism of Ultraviolet Bonding of Perfluoropolyether Lubricants," IEEE Trans. Mag., 29, 1993, 282-285.

[4] Hong, T. and Matsudaira, T., “Tribological Characteristics of Liquid Lubricant on Magnetic Disks Treated by Far-UV Radiation," Trans. ASME, J. of Tribology, 115, 1993, 400-405.

[5] Zhao, X., Bhushan, B. and Kajdas, C., "Lubrication Studies of Head-Disk Interfaces in a Controlled Environment Part2: Degradation Mechanisms of Perfluoropolyether Lubricants," Proc. Instn. Mech. Engrs. Part J: Journal of Engineering Tribology, 214, 2000, 547-559.

[6] Zhao, X. and Bhushan, B., "Studies on Degradation Mechanisms of Lubricants for Magnetic Thin-Film Rigid Disks," Proc. Instn. Mech. Engrs. Part J: Journal of Engineering Tribology, 215, 2001, 173-188.

[7] Zhu, L., Liew, T. and Chong, C. T., "Pulsed UV-Laser-Induced Chemistry of Perfluoropolyether Lubricant Film," Appl. Phys. A 75, 2002, 633-636.

[8] Chiba, H., Nakamura, N., Takeda, M. and Watanabe, K., "Effects of Vacuum Ultraviolet Irradiation to Lubricant Layer on Hard-Disk Media," IEEE Trans. Mag., 38, 5, 2002, 2108-2110.

[9] Chiba, H., Nakamura, N., Takeda, M. and Watanabe, K., "Improvements of Lubricant Performance in Hard-Disk Media by Vacuum Ultraviolet Irradiation," Tribology International, 36, 2003, 367-369.

[10] Zhang, H., Mitsuya, Y., Imamura, M. and Fukuzawa, K., "Effect of Ultraviolet Irradiation on the Interactions between Perfluoropolyethers Lubricant and Magnetic Disk Surfaces," Tribology Letters, 20, 2005, 191-199.

[11] Wakabayashi, A., Shimizu, T., Kobayashi, M. and Kasai, P. H., "UV Bonding of Hard Disk Lubricants; Characteristic and Mechanism," Proceeding of ASIATRIB 2006 Kanazawa, 2, 2006, 603-604.

[12] Guo, X. C. and Waltman, R. J., "Mechanism of Ultraviolet Bonding of Perfluoropolyethers Revisited," Langmuir, 23, 2007, 4293-4295.

[13] Waltman, R. J. and Guo, X. C., "The PhotoDissociation of Perfluoropolyethers by Ultraviolet Light," Tribology Letters, 27, 2007, 227-231. 